\title{
Disease resistance and enzyme heterozygosity in rainbow trout
}

\author{
Moira M. Ferguson and \\ Lenore R. Drahushchak
}

Department of Zoology, University of Guelph, Guelph, Ontario, Canada N1G 2W1.

The relationship between heterozygosity at nine polymorphic enzyme loci and disease resistance was examined in 373 individually identified rainbow trout (Oncorhynchus mykiss) from 12 full-sib families and a pooled gamete cross. These fish were challenged with bacterial gill disease, a potentially lethal epizootic in freshwater fishes. The 213 surviving fish had significantly greater numbers of heterozygous loci per fish and were significantly larger than the 160 individuals that died. Survivors, on average, had higher heterozygosity at six out of nine loci than non-survivors. The differences were significant at three of these loci. These findings suggest that more heterozygous rainbow trout have superior disease resistance than less heterozygous fish.

\section{INTRODUCTION}

The significance of the large amounts of variation at enzyme coding loci in natural populations is an important question in evolutionary genetics. Two classes of hypotheses, neutrality and natural selection have been invoked to explain the significance of this variation. One approach to distinguish between these hypotheses has been to compare the values of fitness components in multilocus heterozygotes and homozygotes (reviews: Mitton and Grant, 1986; Allendorf and Leary, 1986; Zouros, 1987; Zouros and Foltz, 1987). The enhanced survival of heterozygotes has been most commonly inferred from temporal changes in heterozygosity within a cohort. For example, western toads (Bufo boreas) collected in the spring had greater average heterozygosity than those from the same cohort collected the previous autumn suggesting that heterozygotes had greater resistance to environmental stress (Samollow and Soulé, 1983). Even though emigration and immigration can reasonably be excluded as causes of the change, it cannot be firmly established that the individuals that did not survive were relatively homozygous compared to the sampled toads.

A direct approach is to examine the multilocus heterozygosity of marked individuals that live or die in response to a known selective agent such as an epizootic. A few convincing examples of associ- ations between disease resistance and heterozygosity at single loci exist (Allison, 1955; Frelinger, 1972; Wills, 1981). For example, female pigeons (Columba livia) heterozygous at a transferrin locus hatch a larger percentage of their eggs than homozygous females (Frelinger, 1972). The offspring of heterozygotes show greater resistance to embryonic and early posthatching microbial infections. We are not aware, however, of any studies showing a direct relationship between disease resistance and multilocus heterozygosity. In this study, we show that rainbow trout (Oncorhynchus mykiss) that survived an epizootic are significantly more heterozygous and larger than those that died.

\section{MATERIALS AND METHODS}

\section{Experimental fish}

A pooled gamete cross ( 25 females $\times 25$ males $)$ and 12 full-sib families were made on 15 April 1987 with gametes from rainbow trout collected from the Ganaraska River, Ontario. The Ganaraska population is a relatively large self-sustaining population; over 10,000 fish were counted in the river during the spawning run of 1988 (Ontario Ministry of Natural Resources, personal communication). There is no evidence of population subdivision because no deviations from Hardy- 
Weinberg proportions have been observed (Ferguson, 1990). In addition, the fish in the Ganaraska River have relatively high amounts of protein polymorphism compared to other rainbow trout (Ferguson et al., 1985).

The progeny were reared separately by cross in the laboratory for 11 months after fertilization. Fish from each cross were tagged anterior to the dorsal fin with individually numbered fingerling tags (Floy Tag Co., Seattle, WA). From 19 to 34 fish from each family (mean initial fork length per family: $12 \cdot 4-13.9 \mathrm{~cm}$ ), and 62 from the pooled cross (mean length: $13.6 \mathrm{~cm}) \quad($ Total $=373$ ) retained their tags throughout the experiment. All tagged fish were reared in the common environment of a 2445 litre tank with a flow through well water system and fed excess rations of commercial trout food.

\section{The epizootic-bacterial gill disease}

At approximately one month after tagging, a flush of particulates through the water system coincided with an outbreak of bacterial gill disease (Schachte, 1983). The onset of bacterial gill disease usually follows a deterioration of environmental conditions. Bacterial gill disease is characterized by filamentous bacteria (e.g., Flavobacterium spp.) on the gills accompanied by fusing and clubbing of the gill filaments. The infection is accompanied by loss of appetite, lethargy, and gathering of fish near the water surface. Acute outbreaks may involve daily mortality rates of $20-50$ per cent. Bacterial gill disease is one of the most prevalent diseases in hatchery populations of salmonids.

Despite treatment with the anti-bacterial agent, Chloramine-T (From, 1980) at the onset of symptoms, 160 fish died within the next month. The dead fish were collected and frozen at $-80^{\circ} \mathrm{C}$ within hours of death. The 213 survivors were reared for an additional 3 months, killed with an overdose of anesthetic, and stored at $-80^{\circ} \mathrm{C}$. The extended rearing of the survivors ensured that no additional bacterial gill disease related deaths occurred.

\section{Electrophoresis}

The following polymorphic enzymes and loci were examined in all survivors and non-survivors with horizontal starch gel electrophoresis (Allendorf et al., 1977): glycerol-3-phosphate dehydrogenase $(G 3 p 1)$, glycyl-leucine peptidase (Gl1), hexosaminidase $(\mathrm{Hex})$, isocitrate dehydrogenase (Idh2 and Idh 3,4), malate dehydrogenase
$(M d h 3,4)$, phosphoglucomutase (Pgm2), phosphoglycerate kinase $(P g k 2)$, and superoxide dismutase $(S o d)$. An additional 50 enzyme loci are monomorphic in Ganaraska rainbow trout (Ferguson, 1990).

Each of the two pairs of duplicated loci (Idh3,4; Mdh3,4) (Allendorf and Thorgaard, 1984), was treated as a single tetrasomic locus in all analyses. Thus, homozygotes have only a single electromorph for both loci while heterozygotes show two or more electromorphs.

\section{RESULTS}

\section{Heterozygosity}

We first tested if survivors and non-survivors differed in the number of heterozygous loci per fish. We predicted that survivors would be more heterozygous than non-survivors. The first analysis was based upon the 311 progeny from the 12 families. The variation in the number of heterozygous loci per fish (range: $0-7$ ) was partitioned by a two-way ANOVA (least squares) into (1) family [12 treatments] and (2) survival class [two treatments] effects. Survivors were significantly more heterozygous than non-survivors in family progeny $\left(F=3.84, \mathrm{df}=1,298\right.$; one-tailed $\left.P\left[P_{1}\right]=0.025\right)$. Survivors had higher mean heterozygosity than non-survivors in seven out of 12 families (table 1).

The two-way ANOVA was then expanded to include the 62 progeny from the pooled gamete cross. In this analysis, the numbers of heterozygous loci per fish was partitioned among (1) progeny groups [13 treatments] and (2) survival classes [two treatments]. Again, the survivors were significantly more heterozygous than non-survivors $\left(F=4 \cdot 92, \mathrm{df}=1,359, P_{1}=0 \cdot 014\right)$.

In a third analysis, the number of heterozygous loci per fish in survivors and non-survivors were compared within the pooled gamete cross with a $t$-test. Even though not statistically significant $(t=$ $1 \cdot 036, \mathrm{df}=60, P_{1}=0 \cdot 152$ ), survivors had higher mean heterozygosity than non-survivors (table 1).

\section{Single locus effects}

We determined the relative contribution of specific loci by comparing the number of homozygotes and heterozygotes in survivors and non-survivors within each progeny group with a Contingency $G$-test $(2 \times 2$ table $)$. The $G$-values and degrees of freedom from each of the progeny groups segregating at each locus were then summed to determine the overall significance per locus. 
Table 1 Mean initial fork lengths $(\mathrm{cm})$ and numbers of heterozygous loci per fish (Het.) of rainbow trout from a pooled gamete mating ( 25 female $\times 25$ males) or 12 full-sib families that either survived or died in response to an epizootic

\begin{tabular}{|c|c|c|c|c|c|c|c|}
\hline \multirow{2}{*}{$\begin{array}{l}\text { Progeny } \\
\text { group }\end{array}$} & \multirow{2}{*}{$\begin{array}{l}\text { No. } \\
\text { Polymorphic } \\
\text { loci }\end{array}$} & \multicolumn{3}{|c|}{ Survivors } & \multicolumn{3}{|c|}{ Non-survivors } \\
\hline & & Length & Het. & $N$ & Length & Het. & $N$ \\
\hline \multicolumn{8}{|l|}{ Family } \\
\hline A37 & 5 & $14 \cdot 38$ & $3 \cdot 12$ & 17 & $13 \cdot 08$ & $2 \cdot 17$ & 12 \\
\hline A39 & 4 & $13 \cdot 42$ & $2 \cdot 91$ & 11 & $12 \cdot 23$ & $3 \cdot 13$ & 23 \\
\hline A41 & 6 & $13 \cdot 60$ & $3 \cdot 20$ & 20 & $13 \cdot 04$ & $2 \cdot 89$ & 9 \\
\hline A42 & 3 & $12 \cdot 50$ & $3 \cdot 64$ & 14 & $12 \cdot 12$ & $2 \cdot 80$ & 5 \\
\hline A43 & 5 & 13.69 & $2 \cdot 62$ & 13 & $11 \cdot 86$ & $2 \cdot 64$ & 11 \\
\hline A46 & 7 & $12 \cdot 76$ & $3 \cdot 86$ & 7 & $12 \cdot 25$ & $3 \cdot 14$ & 14 \\
\hline A48 & 5 & $12 \cdot 75$ & $2 \cdot 75$ & 16 & $12 \cdot 81$ & $2 \cdot 86$ & 7 \\
\hline A49 & 6 & $12 \cdot 57$ & 3.63 & 16 & $13 \cdot 08$ & $4 \cdot 20$ & 10 \\
\hline A50 & 5 & $13 \cdot 59$ & $2 \cdot 92$ & 13 & $13 \cdot 55$ & $2 \cdot 55$ & 11 \\
\hline A52 & 6 & $13 \cdot 00$ & $4 \cdot 32$ & 19 & $13 \cdot 21$ & $3 \cdot 00$ & 7 \\
\hline A53 & 3 & $13 \cdot 44$ & $2 \cdot 33$ & 18 & 13.04 & $2 \cdot 43$ & 7 \\
\hline A54 & 5 & $14 \cdot 34$ & $2 \cdot 71$ & 7 & $13 \cdot 33$ & $2 \cdot 54$ & 24 \\
\hline Family Total & 9 & $13 \cdot 32$ & $3 \cdot 18$ & 171 & $12 \cdot 80$ & $2 \cdot 86$ & 140 \\
\hline Pool & 9 & $13 \cdot 58$ & $3 \cdot 41$ & 42 & $13 \cdot 59$ & $3 \cdot 00$ & 20 \\
\hline All Crosses & 9 & $13 \cdot 37$ & $3 \cdot 23$ & 213 & $12 \cdot 89$ & $2 \cdot 88$ & 160 \\
\hline
\end{tabular}

No. polymorphic loci, number of allozyme loci segregating within the family. $N$, total number examined for each cross type.

Table 2 Observed heterozygosity at nine enzyme loci of rainbow trout that survived an epizootic divided by observed heterozygosity of non-survivors ( $H_{\mathrm{rel}}=H_{0}$ sur $/ H_{0}$ non-sur)

\begin{tabular}{|c|c|c|c|c|c|c|}
\hline \multirow[b]{2}{*}{ Locus } & \multicolumn{4}{|c|}{ Cross type } & \multirow{2}{*}{$\begin{array}{l}H_{\mathrm{rel}} \\
\text { Combined } \\
\text { total }\end{array}$} & \multirow[b]{2}{*}{ No. seg. } \\
\hline & $\begin{array}{l}H_{\text {rel }} \\
\text { Pool }\end{array}$ & No. seg. & $\begin{array}{l}H_{\text {rel }} \\
\text { Families }\end{array}$ & No. seg. & & \\
\hline$G 3 p$ & 1.43 & 1 & $2 \cdot 21^{* *}$ & 2 & $1.93^{* *}$ & 3 \\
\hline$G l 1$ & $4 \cdot 76^{*}$ & 1 & $2 \cdot 22^{*}$ & 3 & $2 \cdot 51^{*}$ & 4 \\
\hline Hex & 0.88 & 1 & 0.93 & 9 & 0.91 & 10 \\
\hline $\operatorname{Idh} 2$ & $2 \cdot 38$ & 1 & $1 \cdot 35$ & 6 & $1 \cdot 51$ & 7 \\
\hline$I d h 3,4$ & $1 \cdot 12$ & 1 & $1 \cdot 38^{*}$ & 7 & $1 \cdot 36^{*}$ & 8 \\
\hline$M d h 3,4$ & $1 \cdot 13$ & 1 & 1.03 & 7 & 1.04 & 8 \\
\hline$P g k 2$ & 0.78 & 1 & 0.84 & 10 & 0.81 & 11 \\
\hline Pgm 2 & 0.68 & 1 & $1 \cdot 25$ & 7 & $1 \cdot 13$ & 8 \\
\hline Sod & $1 \cdot 37$ & 1 & 0.85 & 9 & 0.93 & 10 \\
\hline$N$ & 62 & & 311 & & 373 & \\
\hline
\end{tabular}

$N$, total number examined for each cross type.

No. seg., total number of progeny groups with polymorphism at the locus. Numbers of homozygotes and heterozygotes at each locus in the two survival classes were compared with a Contingency $G$-test where $*=P<0.05 ;{ }^{* *} P<0.01$. $G$-values were calculated for each segregating progeny group (No. seg.) and then summed for each locus.

In the analysis of families, survivors were significantly more heterozygous at $G 3 p, G l 1$, and Idh 3,4 (table 2). When the pooled gamete cross was added to the analysis, survivors were significantly more heterozygous at the same loci. Overall, survivors had higher heterozygosity at six loci and lower heterozygosity at three loci than non-survivors. Within the pooled gamete cross, survivors were significantly more heterozygous at Gl1.

\section{Disease resistance and initial body size}

We next tested for a relationship between disease resistance and size by examining the fork lengths of fish at the initiation of the experiment (table 1). 
These data were analysed with two-way ANOVA's and $t$-tests as described above for multilocus heterozygosity. Survivors were significantly longer than non-survivors in families $(F=12 \cdot 35$, df $=$ $\left.1,298, P_{2}=0 \cdot 001\right)$.

In the combined analysis of families and the pooled gamete cross survivors were significantly longer than non-survivors $(F=9 \cdot 38, \mathrm{df}=1,359$, $P_{2}=0 \cdot 002$ ). No significant relationship between survival and size was detectable within the pooled gamete cross. A parallel analysis was conducted for initial fish wet weight and produced statistically identical results (not shown).

\section{Family effects}

We tested if families differed in relative survival by comparing the number of survivors and nonsurvivors among families $(12 \times 2$ table $)$. There was significant heterogeneity among families in the counts of survivors and non-survivors (Contingency $G$-test, $G=39 \cdot 17,11$ df $P<0 \cdot 001$ ) (table 1 ). We next determined if either mean family heterozygosity or mean family fork length was a significant predictor of mean family mortality (Number of non-survivors/total number) with regression analysis. There was no significant regression between mean family heterozygosity (independent variable) and mean family mortality (dependent variable) $\left(F=0.485, \mathrm{df}=1,10, P_{2}=\right.$ $0.502)$. In addition, mean family fork length was not a significant predictor of mean family mortality $\left(F=0 \cdot 001\right.$, df $\left.1,10, P_{2}=0 \cdot 979\right)$.

\section{DISCUSSION}

Our results show that survivors are more heterozygous and larger than non-survivors. These data indicate that more heterozygous and larger rainbow trout show greater disease resistance and survival than less heterozygous and smaller fish. We cannot determine whether the enzyme loci examined or chromosomal segments marked by these loci are responsible for the observed effects.

Previously reported associations between another component of fitness, developmental rate, and heterozygosity in this species suggest that the allozyme loci are marking chromosomal segments that influence developmental rate (Danzmann et al., 1986). The direction of the relationship between heterozygosity and developmental rate was not consistent amongst strains. In some strains, heterozygotes at specific loci hatched significantly sooner than homozygotes while in other strains the opposite was true. In another set of experiments with rainbow trout, Leary et al. (1987) showed that differences in inbreeding coefficients do not explain associations between developmental stability, as measured by fluctuating asymmetry of bilateral meristic characters, and enzyme heterozygosity. As in the present study, Leary et al. (1987) could not determine whether the allozyme loci were directly responsible for the observed effects or were acting as markers of chromosomal segments.

We can therefore only speculate on the genetic and physiological explanations for our results. Fish more heterozygous at enzyme loci may be more heterozygous at loci affecting disease resistance, such as the histocompatibility and blood group loci (Degos et al., 1974; Black and Salzano, 1981; Wills, 1981), than less heterozygous individuals. Increased homozygosity at such loci could make individuals more susceptible to epizootics as many alleles may be required for adequate resistance. For instance, reduced genetic variation has been implicated in the rapid spread of disease in cheetahs (O'Brien et al. 1985). This hypothesis assumes that heterozygosity at the enzyme loci is correlated with heterozygosity at the unknown and presumably large set of loci that affects disease resistance. Chakraborty (1981) developed an expression showing that such correlations are expected to be small. However, Zouros and Foltz (1987) have argued that Chakraborty's (1981) theoretical results may not apply to most studies of enzyme heterozygosity and fitness because the polymorphism at enzyme loci is higher than heterozygosity of the whole set of loci affecting the fitness character. Therefore, heterozygosity at the enzyme loci will make up a greater proportion of the heterozygosity affecting the trait resulting in enzyme heterozygosity being a better predictor of overall heterozygosity.

Interaction between the specific characteristics of bacterial gill disease and the phenotypic or physiological attributes of more heterozygous rainbow trout could be the primary mechanism. As an example, there is evidence that more heterozygous rainbow trout from two strains have lower weight standardized oxygen consumption rates $\dot{\mathrm{VO}}_{2}$ ) and are larger than less heterozygous fish (Danzmann et al. 1987, 1988). These data suggest that more heterozygous fish are metabolically more efficient than less heterozygous individuals. Because bacterial gill disease is associated with death by oxygen deprevation, the increased metabolic efficiency as reflected by reduced $\mathrm{VO}_{2}$ of more heterozygous fish might result in greater resistance to reduced 
oxygen exchange across the gill epithelium during bacterial gill disease infection.

Finally, the family results show that survivors were larger one month prior to the epizootic than non-survivors. Survivors may have resisted bacterial gill disease because of their larger size rather than higher heterozygosity per se. Larger fish are less susceptible to bacterial gill disease than small individuals (Schachte, 1983). According to this hypothesis, heterozygosity remains an important factor in disease resistance because of its association with size. Regardless of the specific mechanism, these data show that genetic variation is an important biological resource to be conserved in captive populations of fishes where disease is likely to be of primary concern.

Acknowledgment This research was supported by a Natural Sciences and Engineering Research Council of Canada operating grant and a Renewable Resources Research Grant from the Ontario Ministry of Natural Resources. We thank $R$. Danzmann, S. Gile, G. Van Der Kraak, A. Liskauskas, and D. Noakes for reading a version of the manuscript and providing many constructive comments.

\section{REFERENCES}

ALlENDORF, F. W. AND LEARY, R. F. 1986. Heterozygosity and fitness in animals. In Soulé, M. E. (ed.) Conservation Bio$\log y$, Sinauer, Sunderland, pp. 57-76.

ALLENDORF, F. W., MITCHELL, N. J., RYMAN, N. AND STÅHL, G. 1977. Isozyme loci in brown trout (Salmo trutta L.): detection and interpretation from population data. Hereditas, 86, 179-190.

ALlendorF, F. W. AND THORGaARD, G. H. 1984. Tetraploidy and the evolution of salmonid fishes. In Turner, B. J. (ed.) Evolutionary Genetics of Fishes, Plenum, New York, pp. 1-53.

ALlison, A. C. 1955. Aspects of polymorphism in man. Cold Spring Harbor Symp. Quant. Biol., 20, 239-255.

BLACK, F. L. AND SALZANO, F. M. 1981. Evidence for heterosis in the HLA system. Am. J. Hum. Genet., 33, 894-899.

CHAKRABORTY, R. 1981. The distribution of the number of heterozygous loci in an individual in natural populations. Genetics, 98, 461-466.

DANZMANN, R. G., FERGUSON, M. M. AND ALLENDORF, F. W. 1986. Does enzyme heterozygosity influence developmental rate in rainbow trout? Heredity, 56, 417-425.
DANZMANN, R. G., FERGUSON, M. M. AND ALLENDORF, F. W. 1987. Heterozygosity and oxygen consumption rate as predictors of growth and developmental rate in rainbow trout. Physiol. Zool., 60, 211-220.

DANZMANN, R. G., FERGUSON, M. M. AND ALLENDORF, F. W. 1988. Heterozygosity and components of fitness in a strain of rainbow trout. Biol. J. Linn. Soc., 33, 285-304.

DEGoS, L., COLOMBONI, J., ChAVENTRE, A., BENGSTON, B. AND JACGUARD, A. 1974. Selective pressure on HLA polymorphism. Nature, 249, 62-63.

FERGUSON, M. M. 1990. Enzyme heterozygosity and growth of rainbow trout reared at two rations. Biol. J. Linn. Soc. (in press).

FERGUSON, M. M., DANZMANN, R. G. AND ALLENDORF, F. W. 1985. Developmental divergence among hatchery strains of rainbow trout (Salmo gairdneri). I. Pure strains. Can. J. Genet. Cytol., 27, 289-297.

FRELINGER, J. A. 1972. The maintenance of transferrin polymorphism in pigeons. Proc. Natl Acad. Sci. USA, 69, 326329.

FROM, J. 1980. Chloramine-T for the control of bacterial gill disease. Prog. Fish-Cult, 42, 85-86.

LEARY, R. F., ALLENDORF, F. W., AND KNUDSEN, K. L. 1987. Differences in inbreeding coefficients do not explain the association between heterozygosity at allozyme loci and developmental stability in rainbow trout. Evolution, 41, 1413-1415.

MITTON, J. B. AND GRANT, M. C. 1984. Associations among protein heterozygosity, growth rate and developmental homoestasis. Ann. Rev. Ecol. Syst., 15, 479-499.

O'BRIEN, S. J., ROELKE, M. E., MARKER, L., NEWMAN, A., WIN KLER, C. A., MELTZER, D., COLLY, L., EVERMANN, J. F., BUSH, M. AND WILDT, D. E. 1985. Genetic basis for species vulnerability in the cheetah. Science, 227, 14281434.

SAMOLLOW, P. B. AND SOULÉ, M. E. 1983. A case of stress related heterozygote superiority in nature. Evolution, 37, 646-649.

SCHACHTE, J. H. 1983. Bacterial gill disease. In Meyer, F. P., Warren, J. W. and Carey, T. G. (eds) A Guide to Integrated Fish Health Management in the Great Lakes Basin, Great Lakes Fishery Commission, Ann Arbor, Michigan, Spec. Pub. 83-2, pp. 181-184.

WILLS, C. 1981. Genetic Variability. Clarendon Press, Oxford. zOUROS, E. 1987. On the relation between heterozygosity and heterosis: An evaluation of the evidence from marine mollusks. In Rattazzi, M. C., Scandalios, J. G. and Whitt, G. S. (eds) Isozymes, vol. 15, Liss, New York, pp. 255-270.

ZOUROS, E. AND FOLTZ, D. W. 1987. The use of allelic isozyme variation for the study of heterosis. In Rattazzi, M. C., Scandalios, J. G. and Whitt, G. S. (eds) Isozymes, vol. 13, Liss, New York, pp. 1-59. 